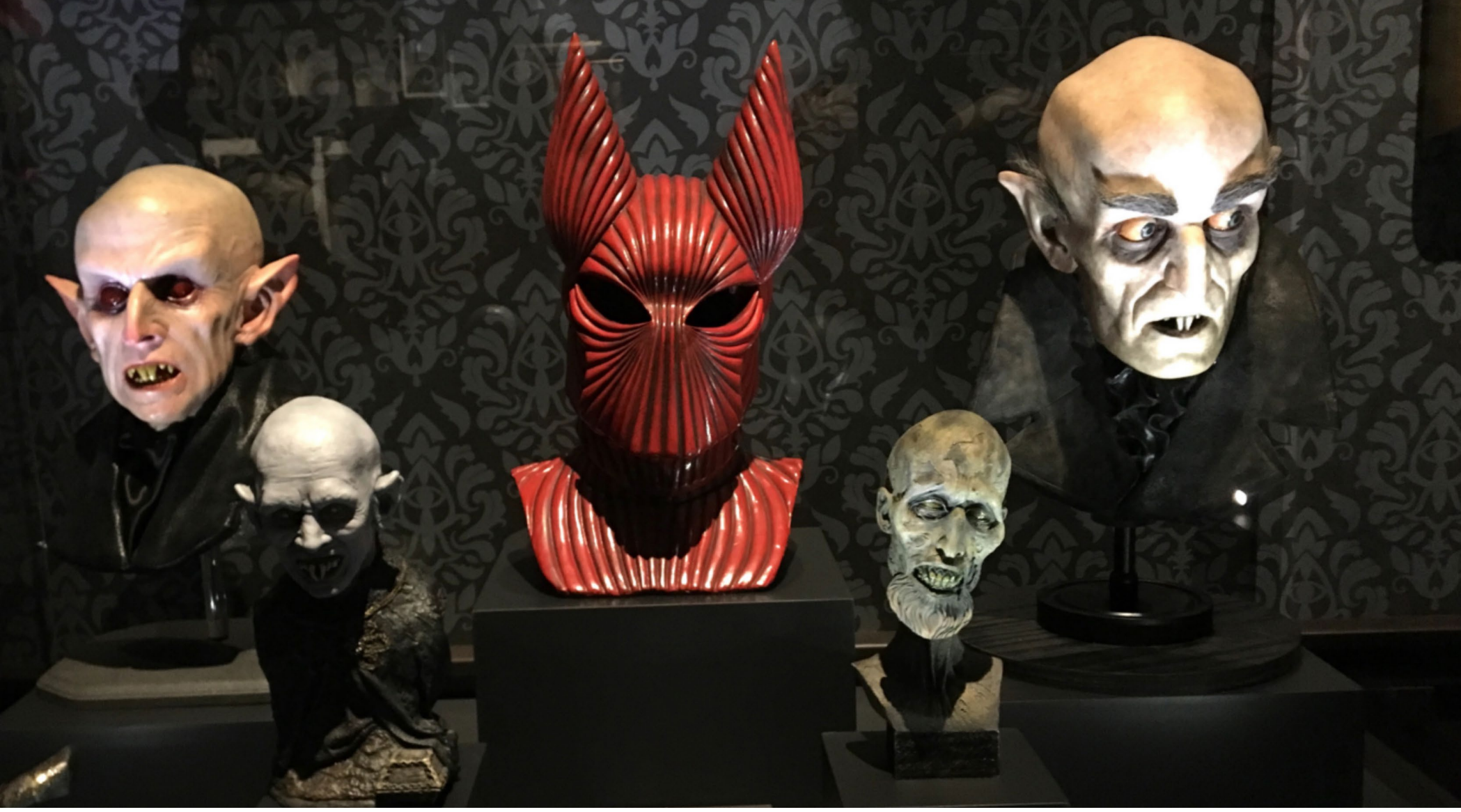

\section{Entre lo espeluznante y lo acogedor. Reseña de la exposición En casa con mis monstruos, de Guillermo del Toro}

Hammurabi HeRnÁNDEZ

alhamra85@yahoo.com.mx

https://doi.org/10.32870/ elojoquepiensa.v0i19.334
En casa con mis monstruos es una exposición compuesta por cerca de 900 piezas que sumergen al visitante en el imaginario de Guillermo del Toro. La exhibición, que cuenta con curaduría de Eugenio Caballero, se celebra en el Museo de las Artes de la Universidad de Guadalajara, y se espera esté abierta al público hasta el 31 de octubre. Es un recorrido que sorprende y abruma al visitante por su extensión, su carácter multimedial, los detalles con que el recinto está decorado, la atmósfera sonora de las salas y, sobre todo, lo expresivo y familiar que resultan muchas de las piezas. El tiempo que dura el recorrido (unas dos horas y media aproximadamente), la abundancia y diversidad de material, así como la cantidad de visitantes que ingresan simultáneamente resultan limitantes para abordar y apreciar con detalle cada una de las obras, todas de igual importancia, por lo que es de esperar que cada persona forme un itinerario distinto y único.

Desde su título, En casa con mis monstruos es una invitación en dos sentidos. Por una parte, la exhibición intenta emular esa sensación entre acogedora y espeluznante que emite el hogar de la colección, un gabinete de curiosidades situado en la ciudad de Los Ángeles que Del Toro denominó "Bleak House", en homenaje al escritor inglés Charles Dickens, y que a días previos de la inauguración corría el riesgo de desaparecer a causa de los intensos 


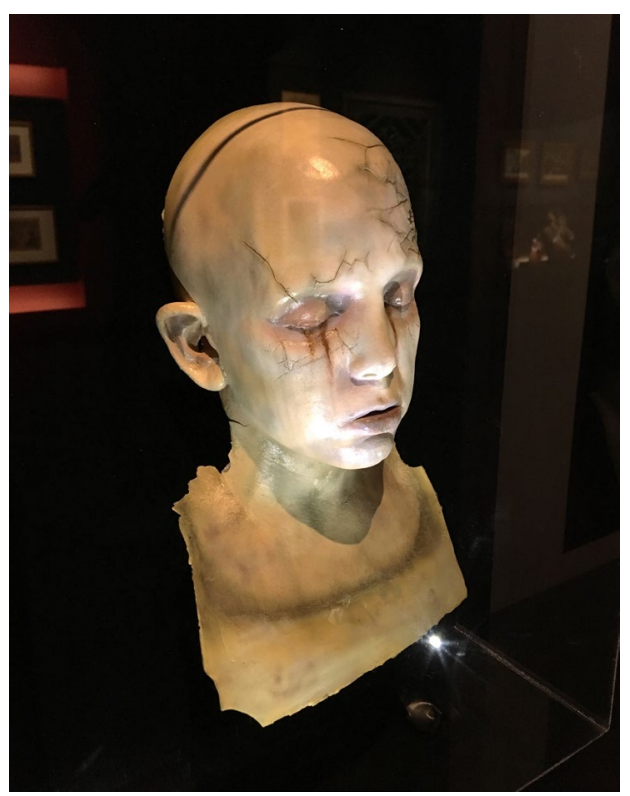

Busto de Santi

El espinazo del diablo (2001). incendios ocurridos en California. La exposición que acontece en Guadalajara no solo salvaguarda una amplia y minuciosa colección de obras de arte sino que funciona como un espacio íntimo y personal, en donde monstruos y demás criaturas dan la bienvenida al visitante con el fin de interpelar una imaginación tan peculiar como la de Guillermo del Toro.

Por otro lado, el título de la exhibición es también un mensaje sobre el regreso al hogar. Oriundo de Guadalajara, Del Toro escogió su ciudad de origen para presentar su colección en México, y la ciudad ha respondido con generosa reciprocidad. Desde largas filas de aficionados y artistas que buscaron obsequiar al realizador alguna pequeña obra de arte de su autoría, a exposiciones alternativas y amateur alrededor de su filmografia, hasta iniciativas como nombrar a una de las principales avenidas con su nombre, en la ciudad de Guadalajara se ha despertado una manía alrededor de la figura del director que la exhibición ha impulsado con creces. Quizá una de las piezas más socorridas sea una escultura con la imagen del propio realizador en el lobby de la exposición y que permite a cada visitante tener un encuentro personal con el afamado director. Como recitan los personajes de Freaks (Tod Brown, 1932), que pueden verse en una de las salas de la exhibición, Guillermo del Toro es "uno de nosotros".

Desde que el director exclamara "porque soy mexicano" ante la pregunta de por qué en sus películas se entremezcla la oscuridad y la esperanza, existe una reivindicación de su filmografía en relación a sus orígenes. La fascinación por los vampiros, los fantasmas o los hombres anfibio resultan la contraparte de la verdadera monstruosidad: la del ser humano, la que instala regímenes autoritarios que atentan contra la libertad y la imperfección. Los monstruos a los que da forma reclaman, ante todo, las inclemencias de la guerra, los dolores guardados, la discriminación o la infancia perdida. Son criaturas que son inconcebibles sin su contexto, tan variado a la vez que universal.

Quizá por ello, a la colección personal del director se suma un amplio corpus proveniente de colecciones particulares, bibliotecas, museos y fundaciones mexicanas que buscan dialogar y contextualizar el imaginario cinematográfico de Del Toro con movimientos artísticos y científicos de nuestro país. A lo largo de la exposición 
se asoman grabados, pinturas e ilustraciones de expositores del modernismo como Ernesto García Cabral, Julio Ruelas, José Clemente Orozco, José Guadalupe Posada, Manuel Manilla, Santiago Hernández, Julio Prieto o Abel Quezada, por mencionar solo algunos. Entre sus obras aparece un variopinto catálogo de fantasmas, demonios o faunos, en su mayoría trabajos que aparecieron en revistas y publicaciones de la época.

Hacia la mitad del recorrido, el visitante se encuentra con un puesto vacío de periódicos y revistas con la marca de El Occidental, uno de los periódicos de mayor longevidad en Guadalajara. Los guías mencionan que el puesto se encontraba en la colonia Americana, a unas cuadras de la casa donde vivió Del Toro de niño, y que es el mismo que atendía para comprar sus historietas. La pieza es un despropósito, o un alargamiento al discurso biográfico que inevitablemente aparece a lo largo de la exposición, pero remite a la importancia que los impresos tuvieron para muchos artistas, entre ellos Del Toro, y la lectura insaciable y la curiosidad infinita como cualidades indispensables para concebir un universo cinematográfico.

En esa línea, se pueden encontrar mesas con primeras ediciones de libros de Juan Rulfo o Mariano Azuela, con la intención de establecer el contexto jalisciense del director. Por lo extraordinario de sus ilustraciones y por esa inusual combinación entre lo cientificista y lo irreal, se exhiben además ediciones facsímiles de libros antiguos como Bestiario de Don Fuan de Austria, atribuido a Martín Villaverde, y Monstruos desde todas partes del mundo antiguo y del moderno, de Giovanni Battista de Cavalieri, así como revistas literarias como El Mosaico mexicano, o colección de amenidades curiosas e instructivas, o El mundo ilustrado, publicación de influencia francesa que sus portadas estaban engalanadas con ilustraciones en el estilo art nouveau.

Entre otras curiosidades, más de corte popular, uno se puede encontrar un cúmulo de la revista Duda, publicación celebrada por sus historias sensacionalistas de misterio, ciencia ficción y parapsicología, la historieta Profesor Planeta, de corte de divulgación científica, y las fotonovelas de Santo. El enmascarado de plata, editadas por José G. Cruz, y responsables de popularizar al luchador mexicano, en donde El Santo, encomendándose a la Virgen de Guadalupe, luchaba contra monstruos y otras criaturas fantásticas. Acompañan a las historietas una colección de máscaras de luchadores

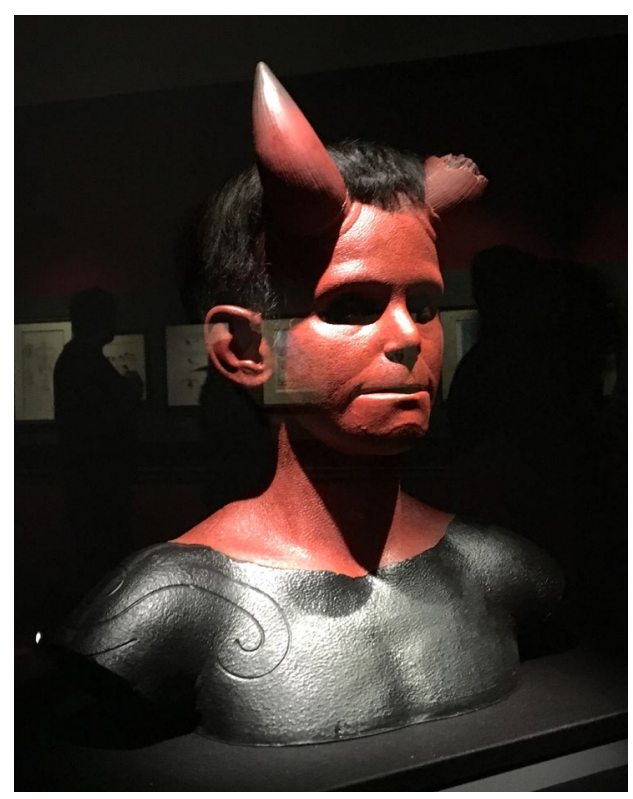

Busto de protagonista de Hellboy (2004). 
mexicanos (entre ellas las de Octagón, Mil Máscaras, El Rayo de Jalisco, Blue Demon, Máscara Sagrada, y varias más), que en el contexto de esta exposición destacan por las formas abstractas con que representan espíritus y demonios.

$\mathrm{Al}$ igual que las mencionadas revistas, otras áreas de la exposición atrapan por su mezcla entre lo racional y lo fantástico, y por su ímpetu por clasificar y describir detalladamente la anormalidad. En ese ámbito, la sala de "Frankenstein", además de incluir esculturas y muñecos del monstruo inventado por Mary Shelley y llevado al cine por James Whale con maquillaje de Jack Pierce, emula un laboratorio de fragmentos de cuerpos enfermos que a la vista son tanto repulsivos como fascinantes. Destacan además una serie de ilustraciones de Bernie Wrightson para una edición especial de la novela de Frankenstein, así como varios diagramas de insectos,

Esculturas sobre

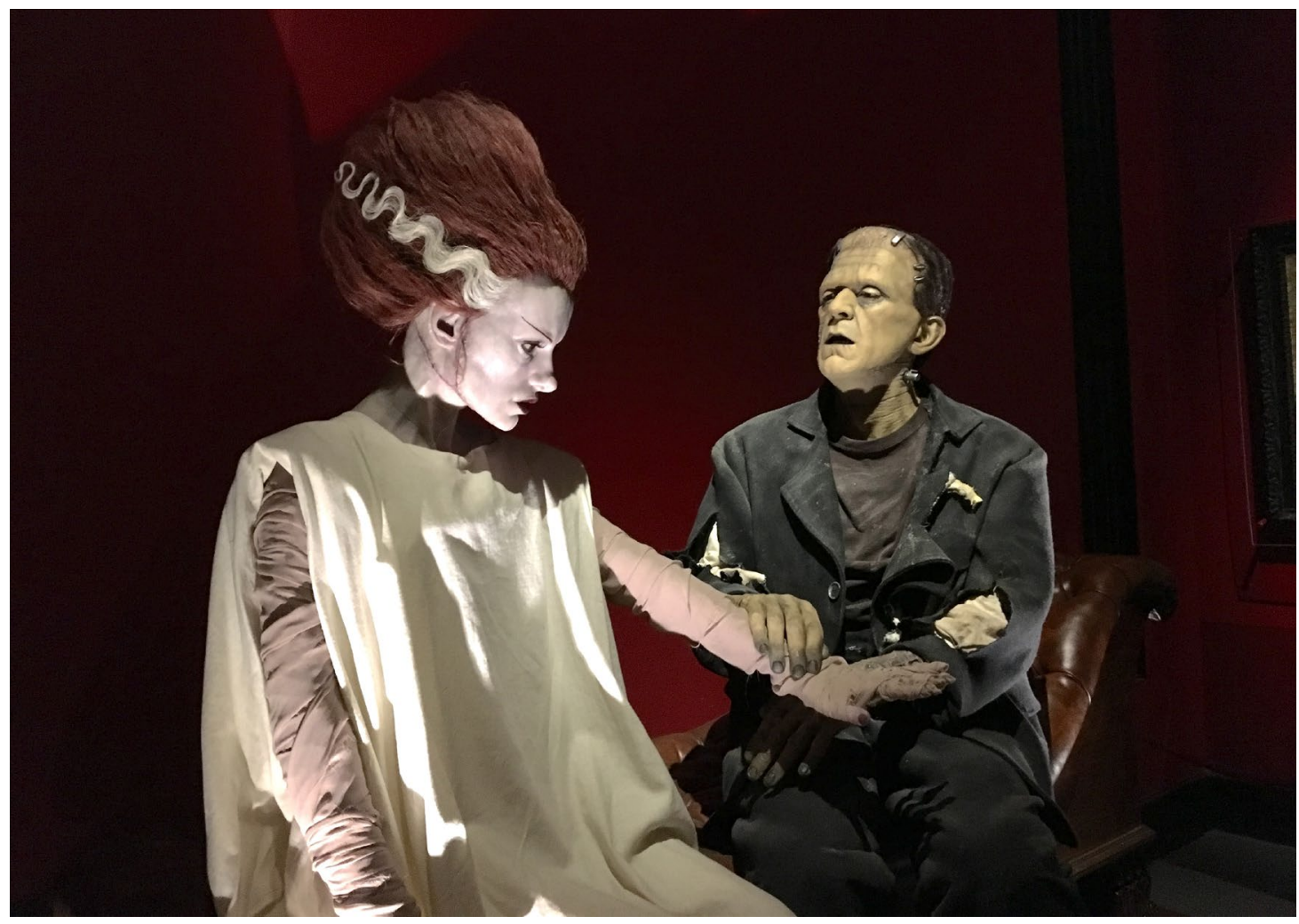


mandrágoras y plantas, y estuches de aparatos e instrumentos médicos perfectamente organizados. La alquimia, los artilugios mágicos y el estudio del cuerpo vampírico aparecen en varios objetos relacionados con La invención de Cronos (1992), como el reloj de oro que sostiene el personaje de Federico Luppi, o bocetos que explican el mecanismo de su funcionamiento.

El interés por el misticismo también se asoma en la sala "Victoriana", que recibe al visitante con una muestra de las vestimentas de la película La cumbre escarlata (Crimson Peak, 2015), diseñados por Kate Hawley; por varias esculturas en resina y diseños conceptuales de los fantasmas que aparecen en la película y que resaltan por su rojiza textura; así como un modelo a escala del vehículo de La máquina del tiempo (The Time Machine, 1960) película dirigida por George Pal. En la misma sala, encontramos varias ilustraciones de Alan Moore y Eddie Campbell para el cómic Desde el infierno (From Hell), situada en la Londres victoriana, acerca del asesino múltiple Jack el Destripador, y un pequeño altar a Charles Dickens a quien se le recuerda en gran medida por, como se mencionó anteriormente, dar nombre original a esta colección.

La literatura gótica tiene su máximo representante en la figura del escritor norteamericano Edgar Allan Poe, cuya presencia se encuentra en el centro del llamado "Cuarto de lluvia". La sala consiste en un cuarto detalladamente adornado, con un ventanal en medio de la habitación desde el que se contempla una fuerte pero apacible tormenta que se emula mediante luces y sonidos. La premisa es que Del Toro solicitó este cuarto en el recinto de Los Ángeles puesto que en aquella ciudad rara vez hay precipitaciones tan intensas como ocurren en Guadalajara, y anhelaba una atmósfera que le recordara ese sentimiento de "estar en casa". Es un bello detalle, pero hace pensar en lo predominante que es el agua en las películas del realizador, y en cómo lo onírico parece empapar a los personajes de formas incontenibles. Entre las ilustraciones que adornan el cuarto se encuentran un cartel preliminar de La forma del agua (The Shape of Water, 2017), filme en donde el amor y el erotismo son de una enorme efervescencia, y el arte conceptual que Paul Julian diseñó para La cumbre escarlata, de una mansión completamente desprotegida por la humedad y que refleja el paisaje interior de los personajes. Del mismo ilustrador, 
quien fuera animador y actor de voz para la Warner Bros., también se pueden contemplar los bocetos que realizó para El corazón delator (The Tell-Tale Heart,1953), cortometraje de animación dirigido por Ted Parmelee, basado en un cuento de Edgar Allan Poe, y una de las primeras películas en recibir clasificación para adultos por el horror psicológico que refleja el protagonista.

El trabajo de ilustradores y diseñadores para el cine de animación prepondera en la exposición. En el cuarto "Infancia" se muestra una valiosa colección de arte conceptual para películas de Disney, en su mayoría del periodo de los 40 y 50, entre los que se incluyen trabajos de Kay Nielsen y Bill Tytla para Fantasía (Fantasia, 1940), Eyvind Earle para La bella durmiente (Sleeping Beauty, Clyde Geronimi, 1959), o Gustav Tenggren para Pinocho (Pinocchio, 1940). Estas últimas despiertan amplia expectativa por la noticia de que Guillermo del Toro está preparando una nueva versión en stop motion del relato de Carlo Collodi. La sala es también recinto para varias obras sobre El laberinto del fauno (2006), como un boceto inicial del árbol al que ingresa Ofelia para recuperar una llave mágica, o una escultura del propio fauno, acomodado de forma que sus sombras se proyecten de forma tenebrosa por las paredes. Aunque no en la misma sala, uno se puede encontrar con cuatro ilustraciones que Stephen Gammell realizó para el libro Historias de miedo para contar en la oscuridad, antología de cuentos de Alvin Schwartz cuya adaptación cinematográfica está producida por Guillermo del Toro, con dirección de André Øvredal. Son obras que además de estar relacionadas a los cuentos de hadas y al folclor, son recordatorio que muchos de estos relatos tienen el horror como su origen, y cómo los niños enfrentan en sus mundos de fantasía de dificultades tan brutales como las de la realidad misma.

Los prospectos por un cine de animación producido en Guadalajara cada vez son más cercanos por el apoyo que el realizador ha otorgado a animadores y realizadores jaliscienses, por la próxima fundación del Centro de Animación, y la entrega de la beca Jenkins-Del Toro, de quien ya se cuentan tres ganadores. La camada de directores de stop motion también participan en la exposición. Así, los protagonistas de Sin sostén (René Castillo, 1998), Jacinta (Karla Castañeda, 2008), Lluvia en los ojos (Rita Basulto, 2012), Zimbo (Juan José Medina y Rita Basulto, 2015), Los aeronautas (León Fernández, 2016), Cerulia (Sofía Carrillo, 2017) y 
Viva el rey (Luis Téllez, 2017) conviven con el titán de bronce y el ejército de esqueletos que el animador Ray Harryhausen empleó para Jasón y los Argonautas (Fason and the Argonauts, Don Chaffey, 1963) en una novedosa combinación de live-action con stop motion.

Los cómics y las historietas también atraviesan toda la exposición. Sorprenden las ilustraciones de artistas como Wayne Barlowe, Sean Andrews, Robert Crumb, Tim Bradstreet, Jim Woodring, Gahan Wilson, Olivier Villoingt, Syd Mead, Basil Gogos o Madeline von Foerster.

En casa con mis monstruos refleja el ímpetu de un sagaz coleccionista, y de la amigable colaboración que ha mantenido con muchos de los artistas expuestos. En ese sentido, una pieza sobresale entre todas. Un retrato en blanco y negro de Hellboy, el antihéroe creado por Mike Mignola, con entusiasta dedicatoria del autor a Guillermo del Toro. "My boy is in good hands". Un regalo, pero también un mensaje de confort y confianza. Un indicio de que todos los monstruos han llegado a casa. 

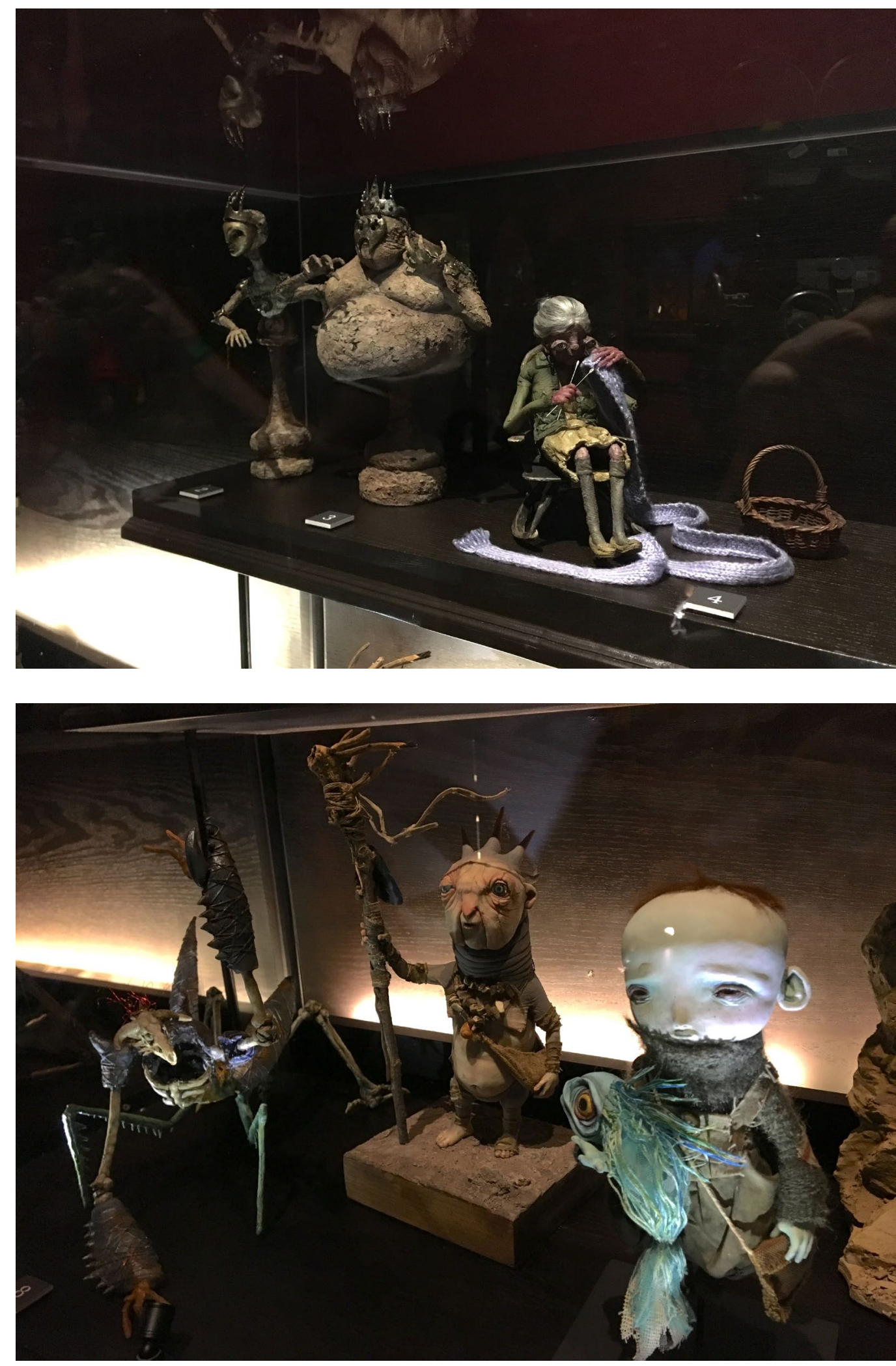

Marionetas diseñadas para

Viva el rey (Luis Téllez, 2017),

Jacinta (Karla Castañeda, 2008),

Los aeronautas (León Fernández, 2016),

y Cerulia (2017). 

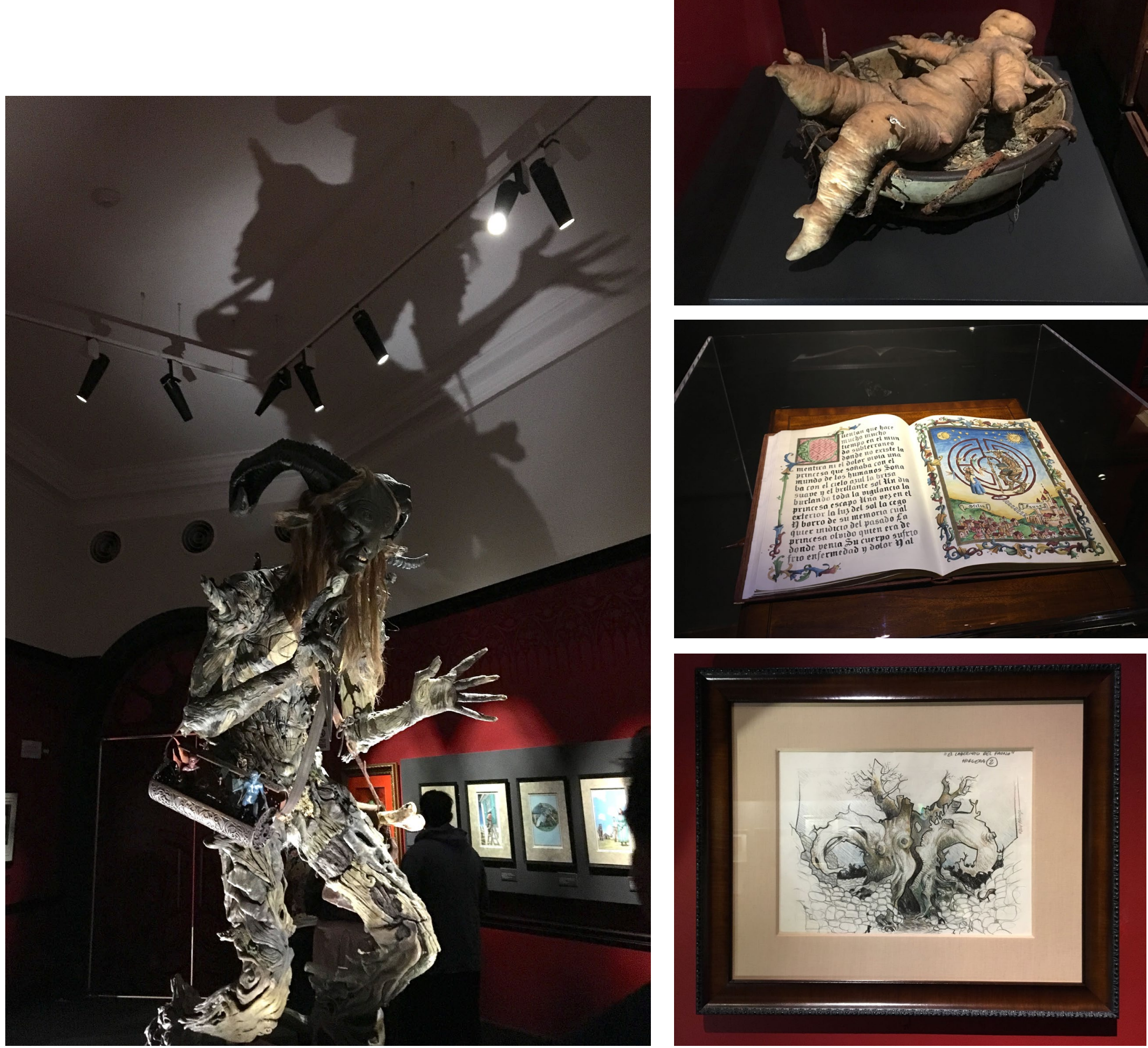

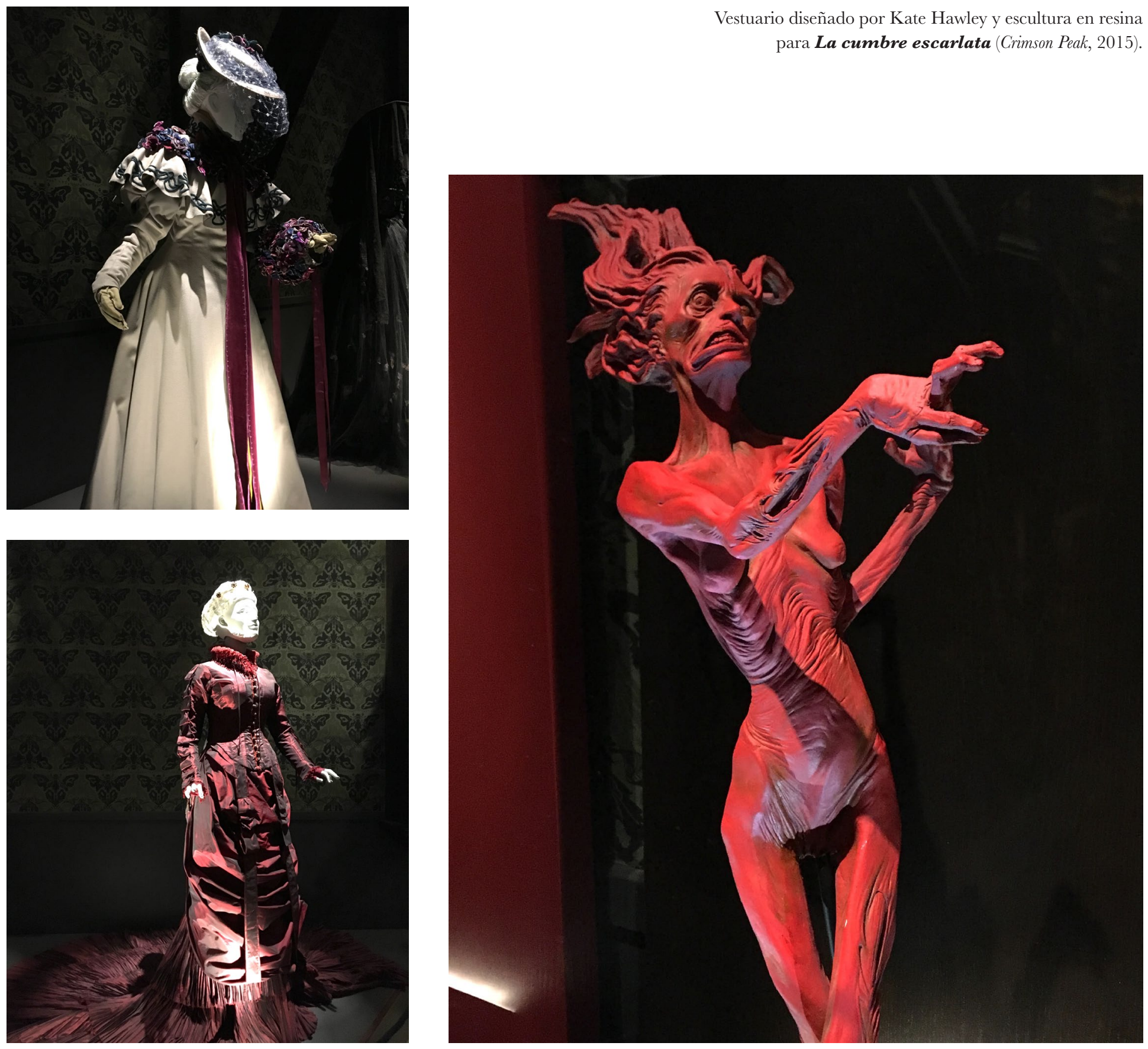


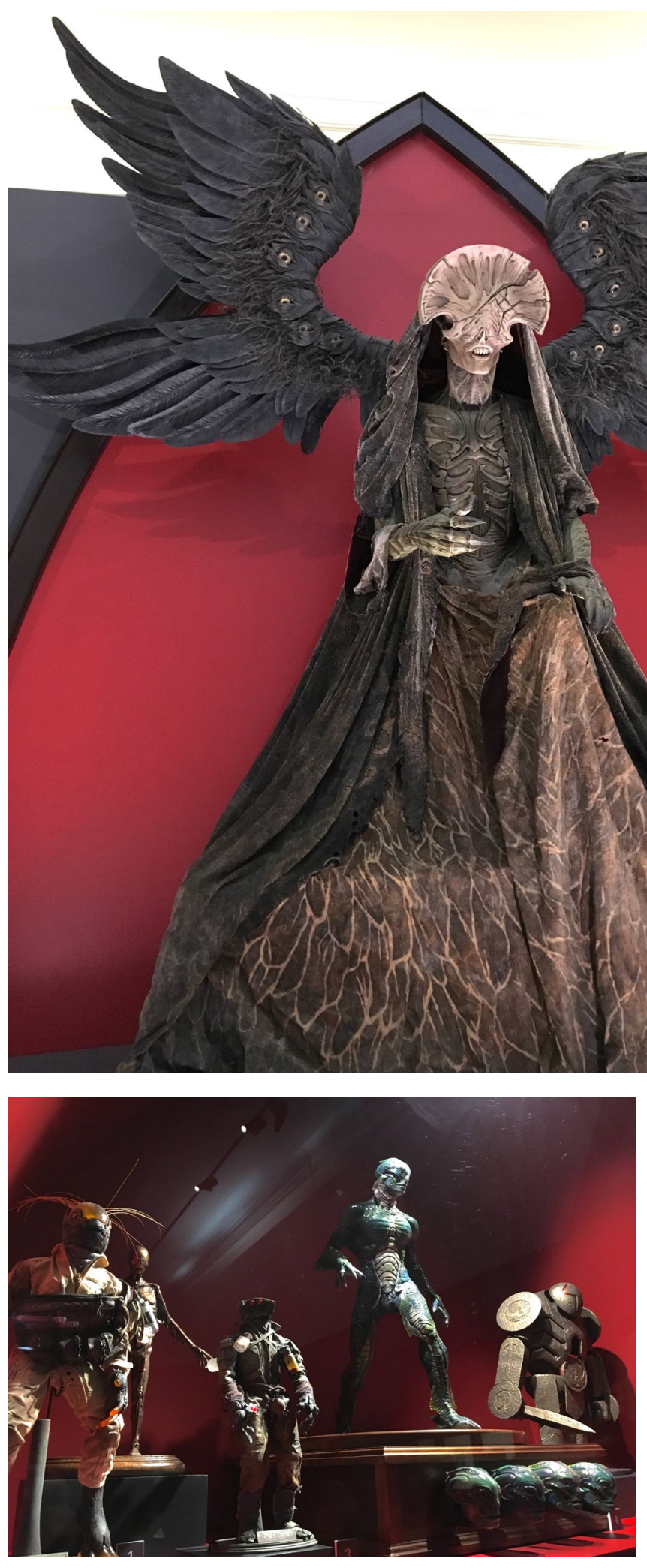

Escultura de El ángel de la muerte y Abe Sapien, y utilería para Hellboy II: El ejército dorado (Hellboy II: The Golden Army, 2008), y retrato de Hellboy por Mike Mignola.
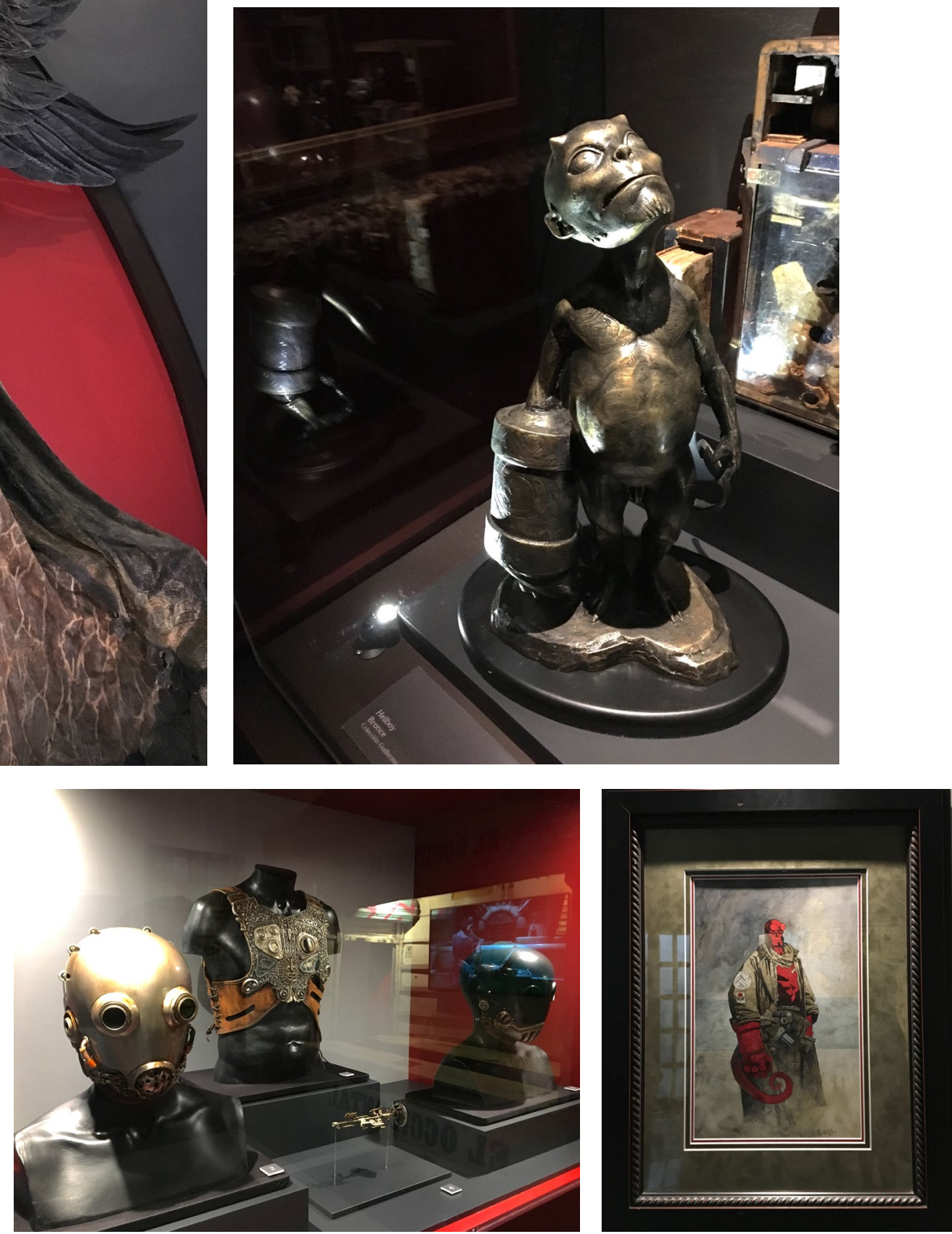

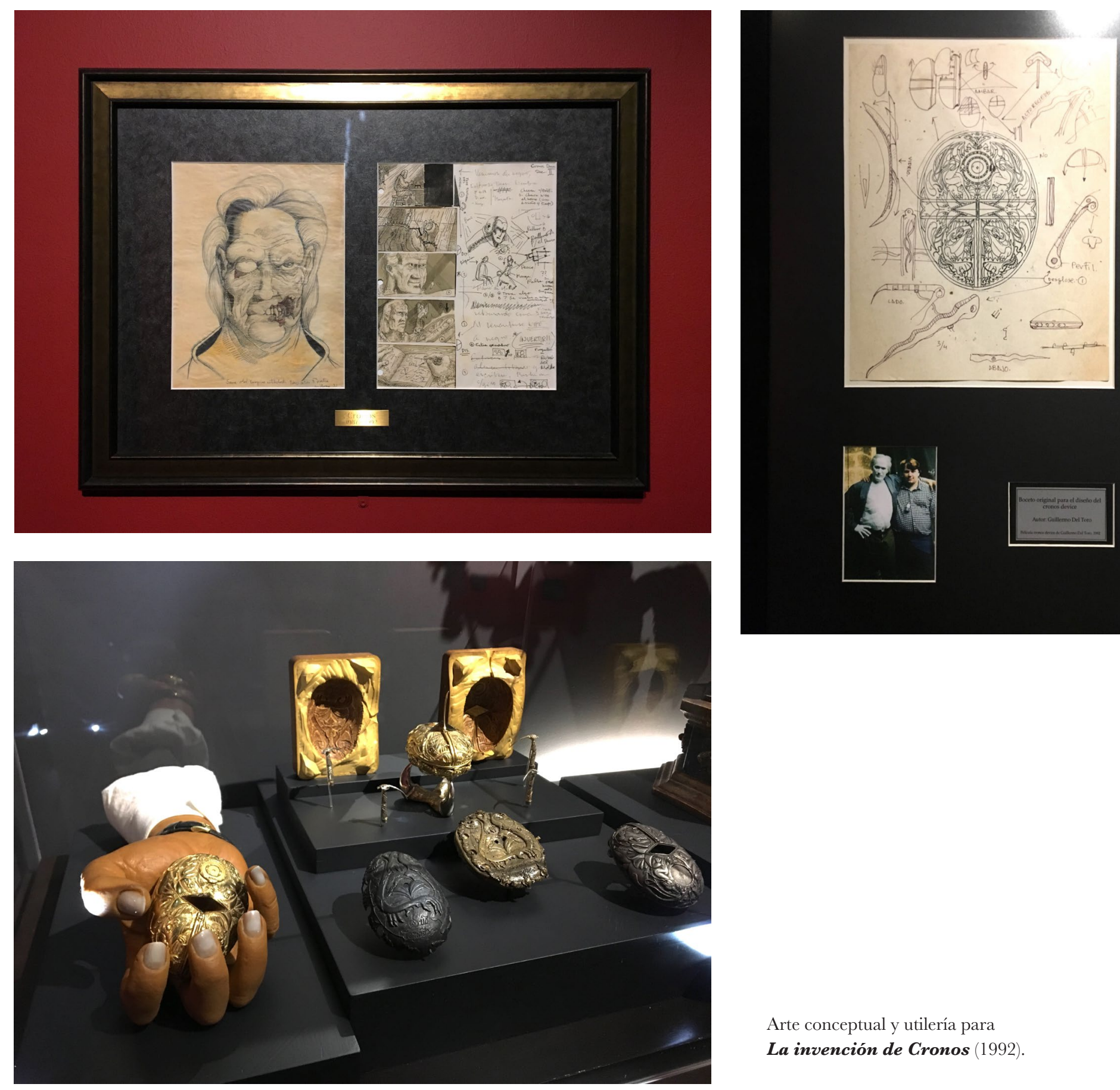

Arte conceptual y utilería para

La invención de Cronos (1992). 

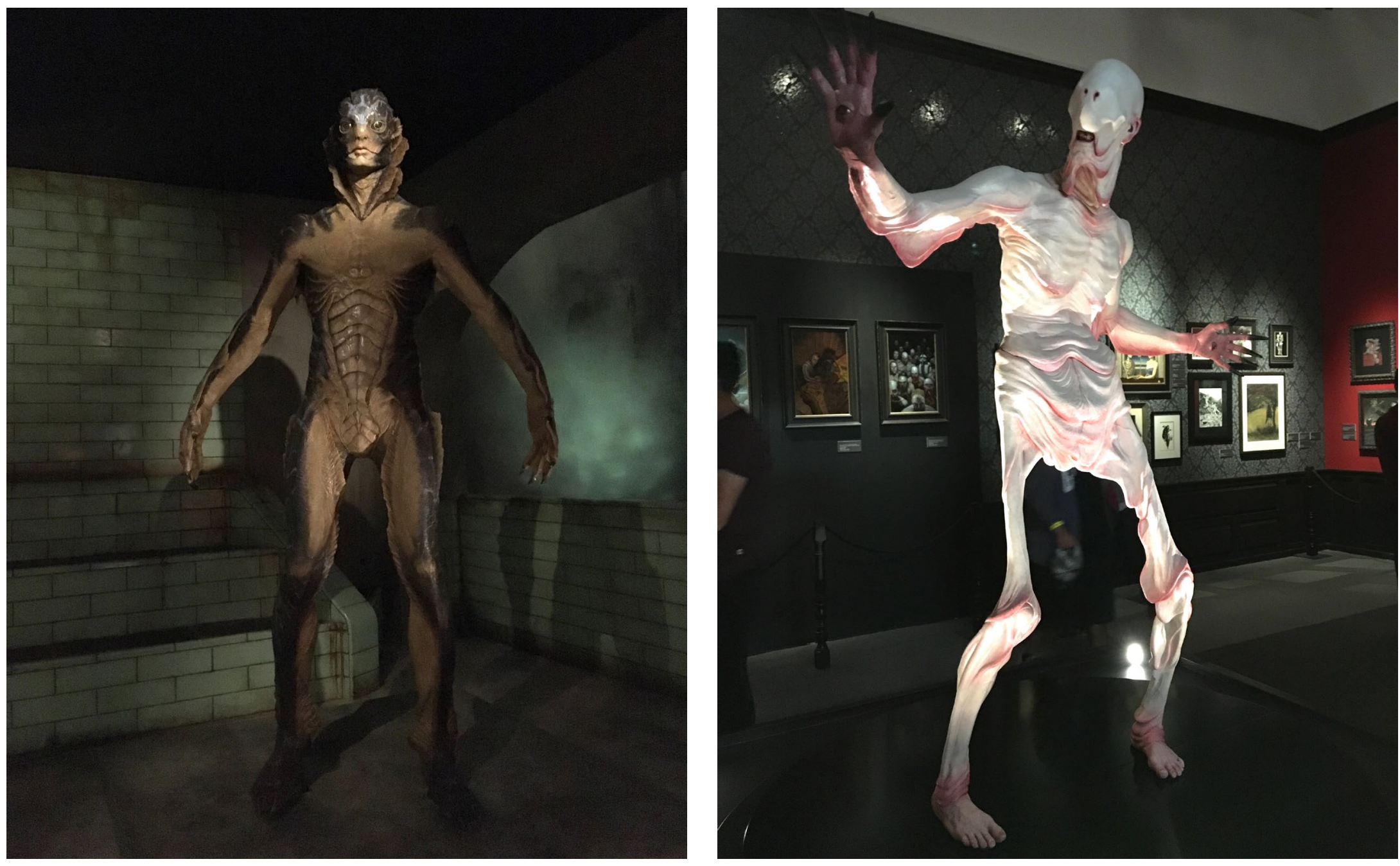

Esculturas del hombre anfibio de La forma del agua (The Shape of Water, 2017) y del Hombre pálido de El laberinto del fauno (2006) 

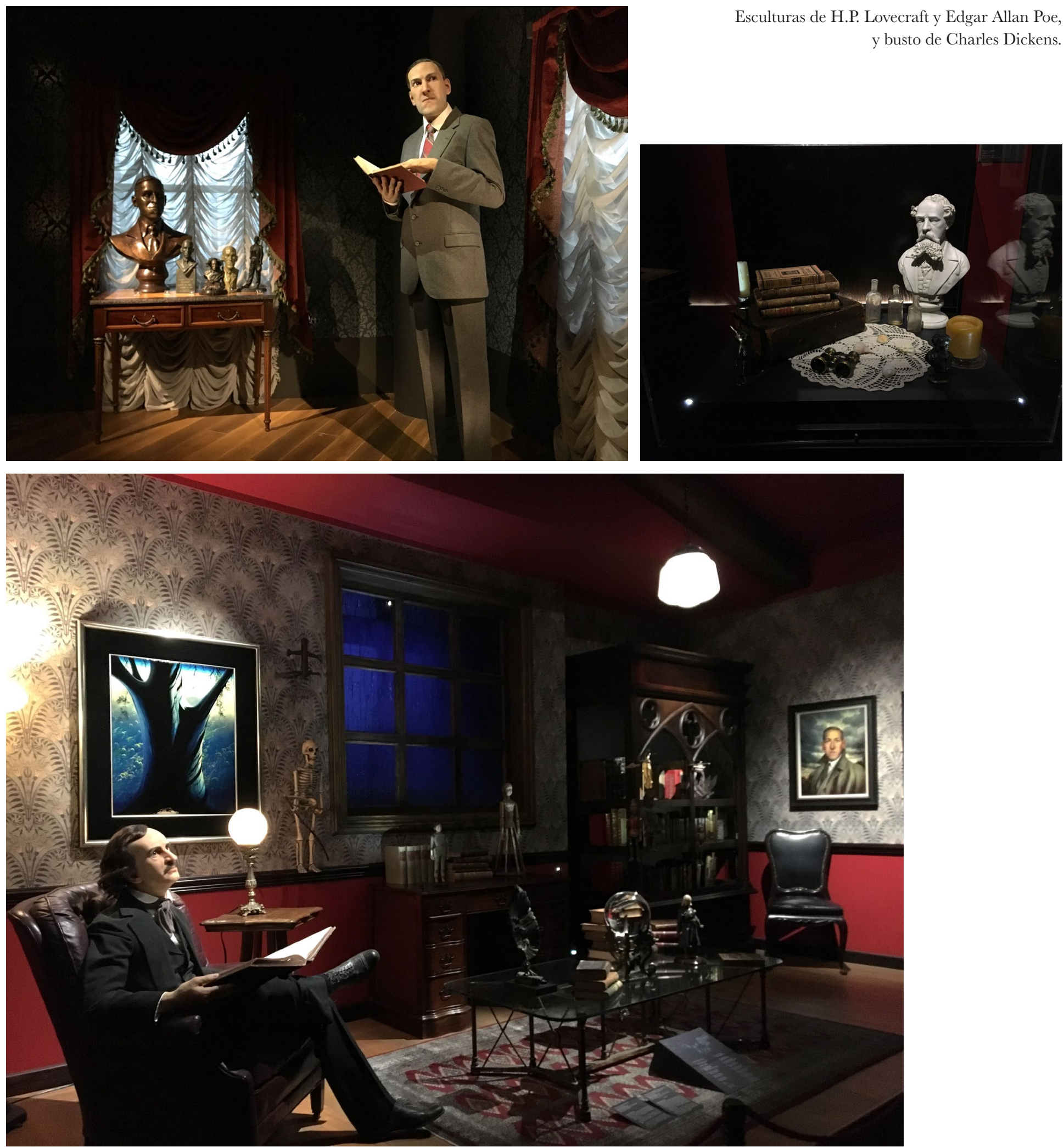

EL OfO QUE PIENSA 
Retrato de Hellboy por Mike Mignola con dedicatoria a Guillermo del Toro / Boceto de Tarzán (Kevin Lima y Chris Buck, 1999) de Glen Keane para Guillermo del Toro / Carta de Hayao Miyazaki dirigida a Guillermo del Toro.
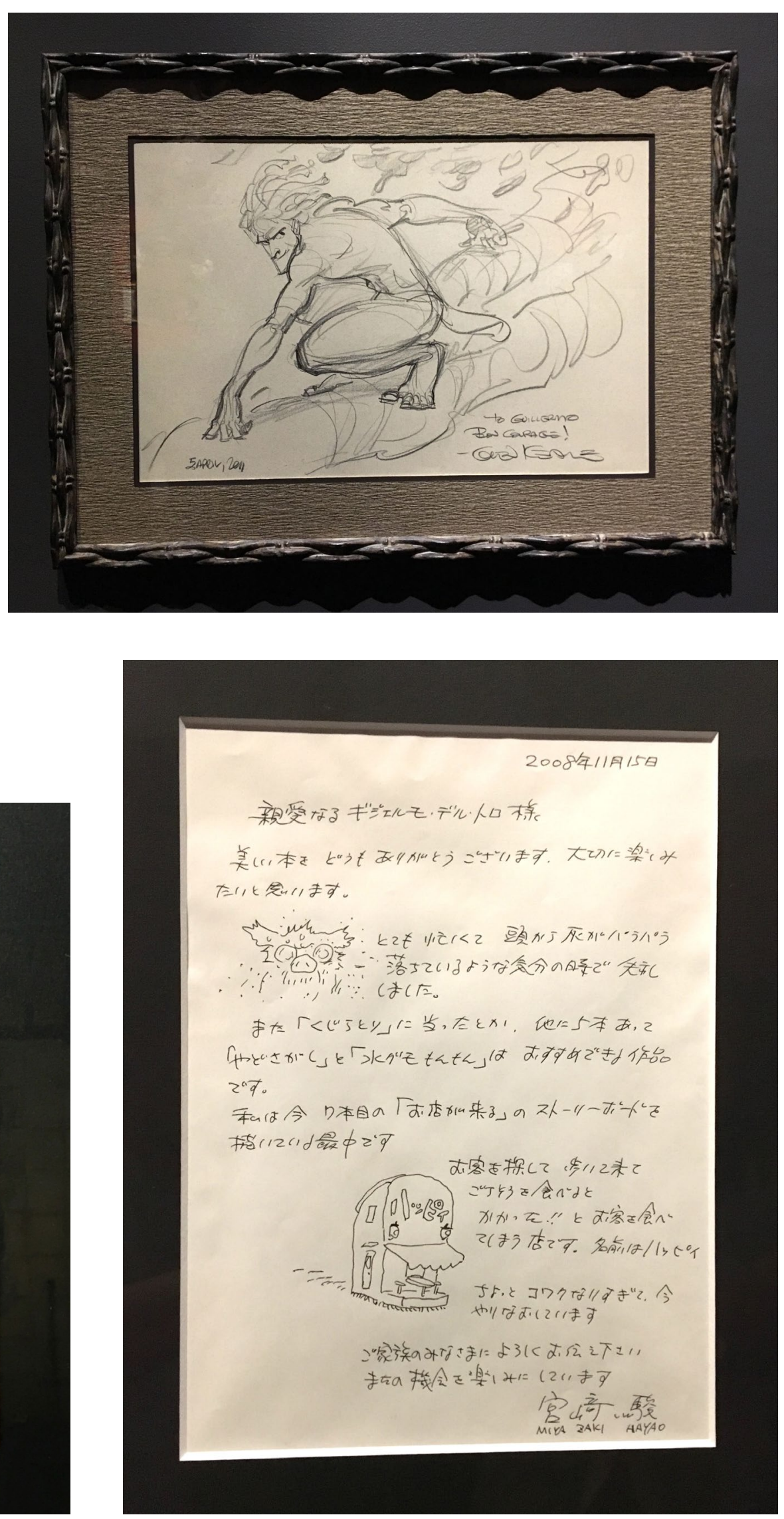
Hammurabi Hernández (México) es Licenciado en Ciencias de la Comunicación por el Instituto Tecnológico y de Estudios Superiores de Occidente. Miembro de la Red de Investigadores de Cine y editor de El ojo que piensa. Revista de cine iberoamericano. Crítico de cine de los periódicos Mural y Reforma. En el 2017 fue seleccionado para participar en el Talent Press del FICG. 